ness of our early categorical imperatives, and in altering the field to which they apply, in the light of reason and experience.

Put in another way, we may say that primitive and absolutist ethics, based on the non-rational and unconscious processes of the mind, inevitably tend to limit human activity by locking up conflicting psychological 'energies' in the repressive mechanism of the unconscious. For constructive and truly humanistic ethics, we need to liberate these forces from their unconscious grappling, through reason and still more by appropriate education and by opportunities for fuller living.

The other point which I would like to make is perhaps even more fundamental. Dr. Waddington writes: "an existence which is essentially evolutionary is itself the justification for an evolution towards a more comprehensive existence". While this is true, it is so general as to smack of Panglossic optimism. It is an observed fact that the majority of evolutionary trends are either irrelevant to progressive change, or are even opposed to it in direction, or are inherently limited specializations. As I have set out at some length elsewhere (in the first essay in my book "The Uniqueness of Man") evolutionary progress can be objectively defined, and further is a rare phenomenon ; the potentialities of further true progress now appear to be restricted to our own species, though there is no guarantee that we shall achieve them. The problem here is thus to study the possible directions of change; to decide which make for progress and which do not ; which make for unlimited and which for limited progress; and to attempt to adjust our social systems and our ethical ideas in such a way that, as Dr. Waddington rightly points out is possible, they should form a mutually reinforcing whole, making for the maximum speed of progress in the correct direction.

Dr. Waddington points out the difficulties arising from the fact that the ethical systems of different societies differ enormously, one conception of the good often contradicting another. Here again there is an evolutionary parallel. Thanks to the work of Sewall Wright, we know that small and isolated animal and plant species will often show 'accidental' differentiation, which is not necessarily biologically advanta eous, and may sometimes even be disadvantageous. The same appears to apply to the evolution of cultures.

Further, as Darlington has pointed out in his recent book, "The Evolution of Genetic Systems", certain evolutionary changes may be of immediate advantage, but of eventual disadvantage in robbing the stock of evolutionary plasticity and adaptability. Here again there are doubtless parallels from ethics. The short-term efficiency of ruthless State dictatorship as opposed to the inevitable long-term triumph of more humanistic systems is a case in point.

With such modifications, Dr. Waddington's thesis of ethical systems as indispensable social organs, derived from the impact of a changing external world on the minds of individuals via the social environment, but themselves then helping to effect changes in the external world and the social environment, appears to be a fundamental one, and worthy of the most careful study. Julian S. HuXley.

Zoological Society of London.

\title{
SCIENCE AND MARXIST PHILOSOPHY
}

$\mathrm{I}_{\mathrm{I}}^{\mathrm{T}}$ $\mathrm{T}$ is a little more than ten years since the London Congress on the History of Science. It was there that the Soviet delegation first brought effectively to the notice of British men of science the contributions that Marxist thought had to make to the natural and social sciences. The symposium organized by Marx House held during August 16-17 has served to show that there is now a widespread and growing interest in this development, and that we are clearly on the way towards a more profound and comprehensive appreciation of science as a human social activity. The two days sessions of the symposium had as keynotes two of Engels' works, "The Dialectics of Nature" and "The Origin of the Family", illustrative of the scientific and sociological aspects of his work.

The first was introduced by Prof. H. Levy, who discussed the changes that the present century has brought about in the attitudes towards philosophy and science, contrasting the older tendencies towards pure science cultivated for its own sake with those of a planned science in the service of the community. He showed how the former tendency is working itself out in the direction of the claims of a priori knowledge, as evidenced in the recent discussion in NATURE between Jeans and Eddington. The majority of men of science, however, are coming more and more to see their activity as part of social enterprise, and to realize that science represents the achievement of human action in an infinite field of ignorance; indeed, that in a sense, the man of science creates new ignorance with every problem he solves. The old absolute views of knowledge and logic are giving way to one in which probability has a much greater part. We need for the advancement of 
science a philosophy that will take all these tendencies into account; and the basis of that philosophy has been laid by Marx and Engels.

Dr. J. Needham provided an interesting analysis of Prof. Whitehead's philosophic opinions. Although Whitehead probably never read Marx, he was led, in attempting to achieve a unitary view of biological and physical phenomena, to an attitude essentially similar to that of the dialectical materialists. In his insistence on the close relation between succession in time and a series of envelopes in space, Whitehead developed a hierarchical series of organizations passing from the purely physical structures of atoms to those of animals, and ultimately societies. Whitehead failed, however, according to Needham, to push his arguments to any practical conclusions, not seeing that any further stages in organization were yet to come.

Prof. J. B. S. Haldane took up the question of the development of science since the writing of "Dialectics of Nature". In that book Engels stressed the chief scientific discoveries-notably the law of the conservation of energy and the theory of evolution-that led to the breakdown of the older and essentially static views of the universe. Haldane carried the analysis on through the achievements of present-day science. He laid particular stress on the fact that the breakdown of boundaries between the different sciences has progressed much further than in Engels' time. The development of modern physics, with its fundamentally dual aspects of wave and particle, fits in particularly well with the dialectical picture that Engels developed. Recent cosmological research has shown that even the laws of physics cannot be taken as fixed and unalterable, but are only so in relation to our very limited experience of time. Everywhere, the picture of the universe as a series of transformations brought about by internal instabilities is gaining ground. The great developments of biochemistry and genetics are providing new links in the chain that joins the inorganic and the organic worlds.

The second day of the symposium was devoted to social and anthropological subjects. Here, as in the natural sciences, a remarkable change has come about in the last few years. Emphasis on the importance of social and economic conditions in anthropological and historical studies has become almost universal. Prof. G. Thomson in his introductory paper provided a brilliant study of that neglected nineteenth-century pioneer, Morgan, the virtual discoverer of the universal form of society, based on clan organization and matrilinear succession, that has preceded our own individualist family organization. Engels took up Morgan enthusiastically in his "Origin of the Family", but more recent anthropological work seems to dis- credit many of Morgan's conclusions. Prof. Thomson discussed these criticisms in the light of the most modern evidence, and showed that though Morgan's view is necessarily limited by the comparatively undeveloped anthropology of his time, his main conclusions have only been confirmed and enlarged. Similarly in physical science, the reaction against the disturbing character of these views led to a sheer obscurantism and the denial of any principles in history or in social development.

Dr. Barbara Ruhemann discussed the economic origins of the universal totemism that accompanies the clan family organization, and further discussion on this subject was provided by papers by Mr. Lionel Naftalin on the relations between slavery and feudalism, and by Prof. Pascal on the gens in primitive Germanic society. All these went to show how rich a clue to the study of social origins is furnished by the work of Morgan and Engels.

The new unification of the sciences and humanities was brought out in a striking way in two papers on medicine presented by Prof. B. Farrington and Dr. Ruscoe Clarke, on the subject of the social significance of medicine in early times, and at the present day. Prof. Farrington traced the way in which medical practice has turned from primitive social health service embodied in practical healing lore to a pretentious and specialized medical practice for the benefit of the rich ; showing how the emergence of a leisured class has distorted the development of medicine. $\mathrm{He}$ pointed out how from the period of the rise of the Greek City State to the eighteenth-century enlightenment, medicine consistently neglected a study of the diseases afflicting the common people, and even more of the special diseases which their conditions of work produced. The breakdown of this attitude began in the eighteenth century with the pioneer studies of industrial diseases by the Italian doctor, Rammztini. Dr. Clarke stated that economic factors in present-day society distort medical practice and theory. Here, again, the inability to solve the real problems of public health in a society which cannot provide basic nutrition and environment has led the older school into a complete denial of medicine as a science, and to the emergence of irrational and mystical elements.

The symposium, to judge from the unexpectedly large attendance and the animated discussions that followed each contribution, must have supplied a need that has existed for some time. There is room, however, for much more effective coordination of the different contributions, and for developments both in the direction of far more thorough discussion among experts, and clearer popular exposition. 